\title{
Continuous biodiesel production I: Trans-Esterification via \\ Sonication
}

IBRO

Blanca Trejo-Muñoz, Minerva U. Martinez, Danaisha Moore, Sivanadane Mandjiny and Steven Singletary

Department of Chemistry and Physics

University of North Carolina at Pembroke, North Carolina 28372-1510

Abstract

Bio-derived fuels such as ethanol and biodiesel, hold the potential to

significantly impact modern society's struggle to provide reliable energy to the world's population and mitigate emission that have a negative effect on climate systems. Biofuel are carbon-neutral and can be easily disturbed using current infrastructure and substituted into existing vehicles, engines, generators, etc. A major obstacle to widespread adoption of biofuels has been cost; biofuel production is expensive due to the batch nature of processing. A simple, continuous and hexpensive production method of biofuels could make them cheaper than fossil fuels and accelerate their adoption.

We report the results of a project designed to develop a continuous production cycle of biodiesel from various old feedstocks. Primary transMetheride mixture is pumped a Methoxide mixture is pumped along a conthuous flow reactor. How speed, triglycerides to methyl-ester (biodiesel).

\section{Introduction}

Biodiesel is a fuel composed of mono-alkyl esters of long chain fatty acids derived from vegetable oils or animals fats, designated B100, and meeting the requirements of the American Society for testing and Materials (1). Store-bought vegetable oil and waste vegetable oil obtained from a loca restaurant were used to synthesize biodiesel at a medium level in UNCPembroke's biochemistry laboratory. The fundamental goal is to learn make biodiesel and the ideal conditions for an appreciable yield. To determine if biodiesel was in fact synthesized, the Gas ChromatographyMass Spectrometry (GC-MS) instrument and bomb calorimetry were utilized.

\section{References Cited}

Hussain, Mohammed Noorul, et. al. Numerical Modeling of Sonicated, Continuous Transesterification and Evaluation of Reaction Kinetics for Optimizing Biodiesel Reactor Design, Int. J. of Thermal \& Environmental Engineering, vol. 11, No. 1, 2016, pp.79-86.

Martinez-Guerra, Edith, et. al. Transesterification of waste vegetable oil under pulse sonication using ethanol, methanol and thanol-methanol mixtures, Waste Management, vol. 34, 2014, pp. 2611-2620. in aqueous acetonitrile solutions. 1414-1418.

Tran, Dang-Thuan, et. al. Recent insights into continuous-flow biodiese

production via catalytic and non-catalytic transesterification processes, Applied

Energy, vol. 185, 2017, pp. 376-409.
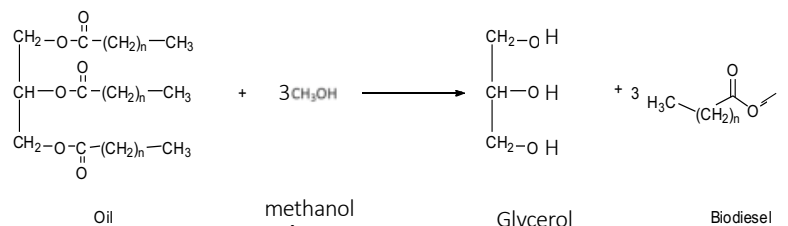

Glycero
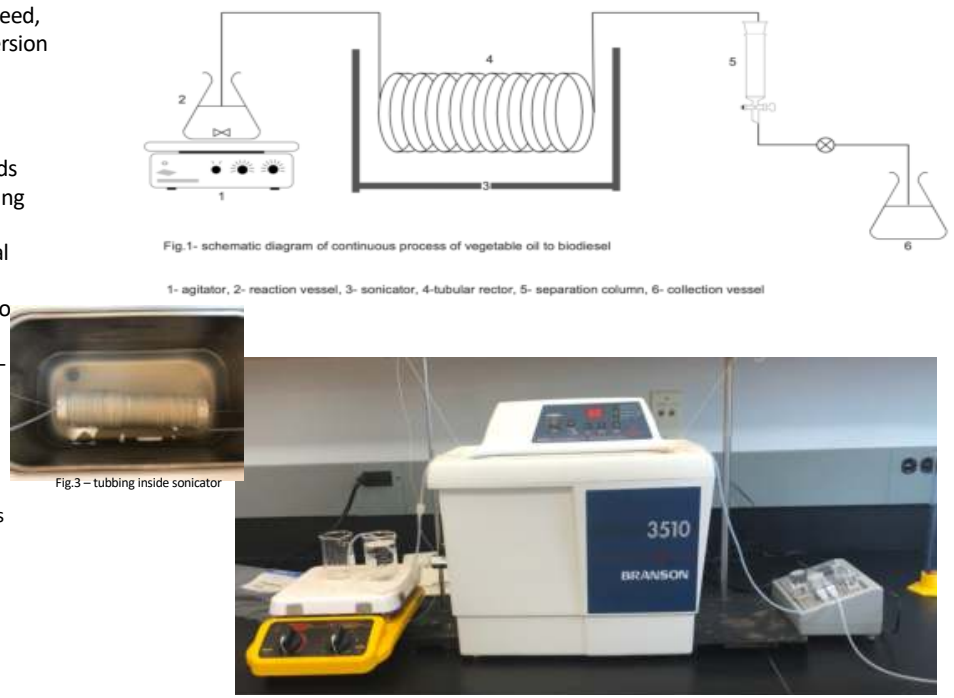

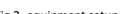

\section{Materials}

To convert vegetable oil into biodegradable diesel, we used the following components: vegetable oil, methanol, and potassium hydroxide.

- Sonicator

- Beaker

- Stand

- Canola oil

- Methanol

- Potassium Hydroxide

- Nalgene 50 silicone tubing

Method

Nalgene silicone tubing of 12.73 meters wound over a PBC tube of $1.5 \mathrm{in}$ external diameter. The temperature is maintained at $65^{\circ} \mathrm{C}$ in the sonicator and the mixture of Vegetable oil, Methanol, and Potassium hydroxide is mixed and passed through the tubular reactor at a flow rate of $12 \mathrm{~mL} / \mathrm{min}$. The mixture was recycled four times and the resulting solution was passed through a packed column containing silica.

Results

Total volume of the reaction mixture to be reacted $=130 \mathrm{~mL}$ Tubular Reactor Holdup Volume $=28 \mathrm{~mL}$

Flow Rate $=12 \mathrm{~mL} / \mathrm{min}$

Time Required for the completion of the reaction $=60 \mathrm{~min}$ Temperature $=65^{\circ} \mathrm{C}$

No of times the solution needs to pass $=130 / 28=4.64$ times

Time required to pass $28 \mathrm{~mL}$ through the holdup volume $=28 / 12=2.33 \mathrm{~min}$ Time required to pass $130 \mathrm{~mL}$ for the reaction $=4.64 * 2.33=10.8 \mathrm{~min}$ 5.5 passes

Discussion

Sonicator helps the molecules to collide faster and efficiently to speed up the reaction due to high frequency. The idea of the tubular reactor is to convert the oil to hiodiesel in a progressive way. The result with five times times recycling is not sufficient for reasonable conversion. The work is in progress to recycle more for better conversion with increased tube length.

Acknowledgments

We would like to thank PURC for granting the travel funds allowing us to attend the ACS guidance throughout this project. We would also like to thank the Dean Dr. Jeff th Frederick, for supporting this work, as well as the entire Department of Chemistry and Physics especially Ms. Carolyn Parsons, at the University of North Carolina at Pembroke. 